\title{
Uso de óxido de cromo como indicador da excreção fecal de bovinos em pastejo: variação das estimativas em função do horário de amostragem
}

\author{
Chromium oxide use as a marker for measuring fecal production of grazing cattle: estimative variations \\ due to sampling schedule
}

\author{
Gilberto Vilmar Kozloski ${ }^{1}$ Diego Perez Netto ${ }^{2}$ Lisandre de Oliveira ${ }^{3}$ Adriano Rudi Maixner ${ }^{2}$ \\ Daniel Terra Leite ${ }^{2}$ Marcieli Maccari ${ }^{2}$ Ivan Luis Brondani ${ }^{4}$ Luis Maria Bonnecarrère \\ Sanchez $^{4}$ Fernando Luiz Ferreira de Quadros ${ }^{4}$
}

\section{RESUMO}

Foi avaliado o efeito dos horários de amostragem sobre as estimativas de excreção fecal, utilizando óxido de cromo como indicador externo, em três experimentos com bovinos em pastejo. Em todos os experimentos foi utilizada uma única dosagem diária (entre 15:00 e 16:00h) de óxido de cromo $(10 \mathrm{~g})$, durante aproximadamente 10 dias, fornecido via oral. O Experimento 1 foi conduzido com vacas da raça Holandês mantidas exclusivamente em pastagem de gramíneas perenes tropicais, e amostras de fezes foram obtidas nos horários 1:00, 5:00, 9:00, 13:00, 17:00 e 21:00h ao longo de um período de 24 horas. Os Experimentos 2 e 3 foram conduzidos com novilhos de corte, cruzas Nelore com Charolês, mantidos em pastagens de gramíneas cultivadas durante 4 a 5 horas/ dia, recebendo ou não suplementação com concentrados, e amostras de fezes foram obtidas nos horários 3:00, 6:00, 9:00, 12:00, 15:00, 18:00, 21:00 e 24:00h ao longo de um período de 24 horas. As concentrações de cromo variaram ao longo do dia, principalmente nos experimentos com novilhos. No entanto, em todos os experimentos as estimativas de excreção fecal calculadas com base em todas ou somente em duas amostragens diárias (no início da manhã e final da tarde) foram semelhantes. Deste modo, a excreção fecal de animais em pastejo pode ser precisamente estimada pelo fornecimento de óxido de cromo somente uma vez ao dia associada a duas amostragens fecais, entre o oitavo e décimo dias do fornecimento do indicador.

Palavras-chave: consumo, novilhos, vacas de leite.

\section{ABSTRACT}

The effect of sampling time on fecal production estimative using the chromium oxide technique was studied in three grazing cattle experiments. Chromium oxide $(10 \mathrm{~g})$ was dosed once daily, between 15:00 and 16:00 h., during a 10 days period. In experiment 1 Holstein cows were kept on tropical grasses and feces samples were collected at 1:00; 5:00; 9:00; 13:00; 17:00; and 21:00h. during a $24 \mathrm{~h}$ period. Experiments 2 and 3 were conducted with Nelore and Charolais crossbreed steers grazing on cultivated grasses during 4 to 5 hours/day, with and without concentrate supplementation. Feces samples were taken at $3: 00 ; 6: 00 ; 9: 00 ; 12: 00 ; 15: 00 ; 18: 00 ; 21: 00$ and 24:00h. Diurnal variations in $\mathrm{Cr}$ concentration were observed, mainly on steers experiments. Nevertheless, estimative based on all samples or just on two samples taken early in the morning and late afternoon produced similar results. It was concluded that fecal excretion of grazing cattle may be estimated by dosing $\mathrm{Cr}_{2} \mathrm{O}_{3}$ only once daily and sampling feces twice daily, between days eight to ten of the dosing period.

Key words: intake, steers, dairy cows.

\section{INTRODUÇÃO}

Em experimentos com animais em pastejo, a estimativa do consumo depende da determinação da digestibilidade do pasto ingerido e da quantificação da excreção fecal. A produção fecal pode ser medida diretamente, pelo uso de bolsas coletoras, ou indiretamente, pelo uso de indicadores externos. Neste último caso, o óxido de cromo tem sido o indicador mais amplamente utilizado. O protocolo mais usual consiste no fornecimento via oral de uma determinada

\footnotetext{
${ }^{1}$ Programa de Pós-graduação em Zootecnia (PPGZ), Universidade Federal de Santa Maria (UFSM), Campus Camobi, 97105-900, Santa Maria, RS, Brasil. Email: kozloski@smail.ufsm.br. Autor para correspondência.

${ }^{2}$ PPGZ, UFSM, Santa Maria, RS, Brasil.

${ }^{3}$ Curso de Medicina Veterinária, UFSM, Santa Maria, RS, Brasil.

${ }^{4}$ Departamento de Zootecnia, UFSM, Santa Maria, RS, Brasil.
} 
quantidade de cromo duas vezes ao dia, durante dez a quinze dias, e amostras de fezes são coletadas do reto dos animais nos últimos três a cinco dias de fornecimento do indicador, também duas vezes ao dia. No entanto, o fornecimento de cromo via oral, particularmente em experimentos com gado de corte, em que os animais são bem menos dóceis e menos adaptados à manipulação, é pouco prático e pode gerar estresse nos mesmos capaz de interferir no pastoreio. O fornecimento de cromo somente uma vez ao dia diminui este problema. No entanto, considerando que a excreção fecal apresenta variações cíclicas ao longo do dia (FAICHNEY, 1972), uma única dosagem diária do indicador associado a amostragens de fezes duas vezes ao dia, sempre nos mesmos horários, pode aumentar o erro da estimativa da excreção fecal. Nesta condição, é possível que amostragens em vários horários de um período de 24 horas possam diminuir o erro associado a esta variação.

Deste modo, foi avaliado o grau de variação da concentração de cromo nas fezes em diferentes horários e a precisão de diferentes protocolos de amostragem sobre as estimativas de produção fecal de animais em pastejo, recebendo óxido de cromo uma vez ao dia.

\section{MATERIAL E MÉTODOS}

Foi avaliado o efeito dos horários de amostragem sobre as estimativas de produção fecal, utilizando óxido de cromo como indicador externo, em três experimentos com bovinos em pastejo. Em todos os experimentos, foi utilizada uma única dosagem diária de óxido de cromo (10g), enrolado em cartuchos de papel e fornecido via oral.

O experimento 1 foi conduzido com 24 vacas da raça Holandês, multíparas, com aproximadamente 120 dias de lactação, alimentadas somente com pastagem de tifton 85 (Cynodon sp.) ou capim elefante anão (Pennisetum purpureum cv. Mott), em sistema de pastejo contínuo com lotação variável, e com água e suplemento mineral permanentemente disponível. A produção fecal foi estimada pelo fornecimento do indicador, após a ordenha da tarde, durante 10 dias. Nos últimos três dias do período, foram coletadas amostras de fezes diretamente do reto, duas vezes ao dia, mas em diferentes horários, de forma a ter amostras a intervalos de 4 horas (1:00, 5:00, 9:00, 13:00, 17:00 e 21:00h) ao longo de um período de 24 horas.

O experimento 2 foi conduzido com 24 novilhos cruzados Charolês com Nelore, de 15 meses de idade e peso vivo médio de $220 \mathrm{~kg}$, mantidos em pastagem de sorgo (Sorghum bicolor cv. lmoench) e suplementados ( $1 \%$ do peso vivo, base matéria seca) com farelo de glúten de milho ou farelo de arroz. Os animais permaneciam na pastagem durante quatro horas pela manhã e então eram recolhidos em piquetes com acesso à água, sal mineral e ao suplemento. $\mathrm{O}$ indicador foi fornecido durante 10 dias, às 15:00h, imediatamente antes de receberem a suplementação. Nos últimos dois dias do período, foram coletadas amostras de fezes diretamente do reto, quatro vezes ao dia, mas em diferentes horários, de forma a ter amostras a intervalos de 3 horas (3:00, 6:00, 9:00, 12:00, 15:00, 18:00, 21:00 e 24:00h) ao longo de um período de 24 horas.

O experimento 3 foi conduzido com 12 novilhos cruzados Nelore com Charolês, de 18 meses de idade e peso vivo médio de $230 \mathrm{~kg}$, mantidos em pastagem de aveia (Avena strigosa) e azevém (Lolium multiflorum) e suplementados (1\% do peso vivo, base matéria seca) com farelo de glúten de milho, farelo de soja ou farinha de mandioca. Os animais permaneciam na pastagem durante cinco horas pela manhã e então eram recolhidos em piquetes com acesso à água, sal mineral e ao suplemento. O indicador foi fornecido durante 12 dias, às 16:00h, imediatamente antes de receberem a suplementação. Nos últimos quatro dias do período, foram coletadas amostras de fezes diretamente do reto, duas vezes ao dia, mas, em diferentes horários, de forma a ter amostras a intervalos de 3 horas (3:00, 6:00, 9:00, 12:00, 15:00, 18:00, 21:00 e 24:00h) ao longo de um período de 24 horas.

Em todos os experimentos, as amostras de fezes foram imediatamente congeladas e, posteriormente, secas em estufa com ar forçado, a aproximadamente $55^{\circ} \mathrm{C}$ durante cinco dias, moídas (peneira de $1 \mathrm{~mm}$ ) e armazenadas para posterior análise. Para determinação do cromo, aproximadamente $0,5 \mathrm{~g}$ de amostra parcialmente seca foi pesada em um becker com capacidade para $25 \mathrm{ml}$, queimada em mufla a $550^{\circ} \mathrm{C}$ durante duas horas, adicionados $5 \mathrm{ml}$ de uma solução contendo $10 \mathrm{~g}$ de molibdato de sódio, $150 \mathrm{ml}$ de água destilada, $150 \mathrm{ml}$ de ácido sulfúrico e $200 \mathrm{ml}$ de ácido perclórico (CZARNOCKI et al., 1961), coberto com bola de vidro e colocado em uma chapa quente a aproximadamente $200^{\circ} \mathrm{C}$. Após a solução passar de uma cor esverdeada para amarelo-alaranjada (em torno de 1 a 2 horas após), o conteúdo foi totalmente transferido para um balão volumétrico de $100 \mathrm{ml}$, lavando-se o bécker várias vezes com água destilada, completado o volume com água destilada, filtrado (papel filtro comum) e uma alíquota coletada para determinação de cromo por espectrofotometria de absorção atômica. A curva padrão foi elaborada por tratar $100 \mathrm{mg}$ de óxido de cromo como as amostras de fezes. 
Os dados de concentração de cromo e de excreção fecal foram submetidos à análise de variância que incluiu no modelo os efeitos dos experimentos, dos horários de amostragem, da sua interação e o erro experimental. A interação não foi significativa e, por conveniência, os dados do experimento com vacas de leite foram analisados separadamente daqueles obtidos com novilhos de corte. Os dados foram então analisados por regressão em relação ao horário de amostragem. Adicionalmente, concentrações médias diárias de cromo e, conseqüentemente de excreção fecal, foram calculadas considerando amostras teoricamente compostas de somente dois horários (9:00 e 17:00h) ou de todos os horários de amostragem ao longo do período de 24 horas, e comparadas pelo teste F (5\% de probabilidade do erro Tipo I). Todas as análises foram feitas utilizando o programa computacional SAS (1996).

\section{RESULTADOS E DISCUSSÃO}

Os resultados das concentrações de cromo nas amostras de fezes obtidas em diferentes horários do dia no experimento com vacas de leite são apresentados na figura $1 \mathrm{e}$, nos experimentos com novilhos de corte, na figura 2. As concentrações de cromo nas fezes das vacas tenderam $(\mathrm{P}=0,11)$ a aumentar curvilinearmente entre 1:00 e 21:00h. Estes resultados indicam que a determinação do indicador em amostras coletadas pela manhã tenderiam a superestimar e, às da tarde e noite, subestimar a produção fecal destes animais. As concentrações de cromo nas fezes dos novilhos de corte, por outro lado, variaram quadraticamente ao longo de um período de 24 horas $(\mathrm{P}<0,05)$, tendo sido observados os maiores valores durante o dia e os menores durante a noite. Neste caso, a excreção fecal seria subestimada se calculada a partir de amostras obtidas durante o dia e superestimadas a partir daquelas obtidas à noite.

Na tabela 1, são apresentados os resultados das concentrações fecais de cromo e das estimativas da produção fecal das vacas com base em amostras fecais compostas de dois ou de seis horários de coleta. $\mathrm{Na}$ tabela 2, são apresentados os resultados dos novilhos obtidos com base em amostras fecais compostas de dois ou de oito horários de coleta ao longo de um período de 24 horas. Em nenhum destes experimentos, as concentrações médias de cromo e, conseqüentemente, as estimativas de excreção fecal de matéria seca, foram influenciadas pelo protocolo de amostragem $(\mathrm{P}>0,05)$.

Em experimentos com animais confinados, é possível concluir sobre a exatidão de diferentes protocolos ou métodos indiretos utilizados para estimar a produção fecal, por comparar estimativas obtidas pelo uso de indicadores com valores obtidos pela coleta total das fezes. No entanto, em experimentos com animais em pastejo, a coleta total de fezes é difícil ou impraticável e, assim, embora não seja prático avaliar a exatidão, é possível avaliar a precisão dos métodos. Deste modo, com o mesmo objetivo do presente estudo, ou seja, diminuir a manipulação e o estresse animal associado à estimativa indireta da produção fecal, DETMANN et al. (2001) também testaram diferentes protocolos de fornecimento de óxido de cromo e de amostragem de fezes em novilhos em pastejo. Verificaram que o fornecimento de cromo uma vez ao dia, com concomitante amostragem fecal, resultou em estimativas de produção fecal inferiores e coeficientes de variação superiores (16 vs.10\%) ao fornecimento e amostragem duas vezes ao dia. No presente estudo, ficou evidente a variabilidade da excreção de cromo ao longo do dia, indicando a necessidade de se obter em amostras representativas destas variações. No experimento com vacas de leite, os coeficientes de variação das estimativas de produção fecal foram similares, independente do protocolo de amostragem utilizado (média de 25\%). No experimento com novilhos, no entanto, o coeficiente de variação da produção fecal média estimada com base em oito amostragens foi relativamente menor que aquela baseada em somente duas amostragens diárias (18 vs 31\%). No presente estudo, quando o indicador foi dosado à tarde, as concentrações de cromo nas amostras obtidas no início da manhã e no final da tarde representaram a média das concentrações de todo o período. No entanto, se o indicador for oferecido em outros horários ou turnos que não meados da tarde, é possível que os dois horários de amostragem que representariam a média da variabilidade diária da excreção do cromo sejam diferentes destes.

\section{CONCLUSÕES}

A produção fecal de animais em pastejo, suplementados ou não, pode ser estimada pelo fornecimento de óxido de cromo somente uma vez ao dia, à tarde, durante oito a dez dias, associada a duas amostragens fecais, uma pela manhã e outra no final da tarde, entre o oitavo e décimo dias do fornecimento do indicador. Contudo, a precisão das estimativas aumenta se amostras de fezes forem coletadas em vários horários de um período de 24 horas.

Ciência Rural, v.36, n.2, mar-abr, 2006. 


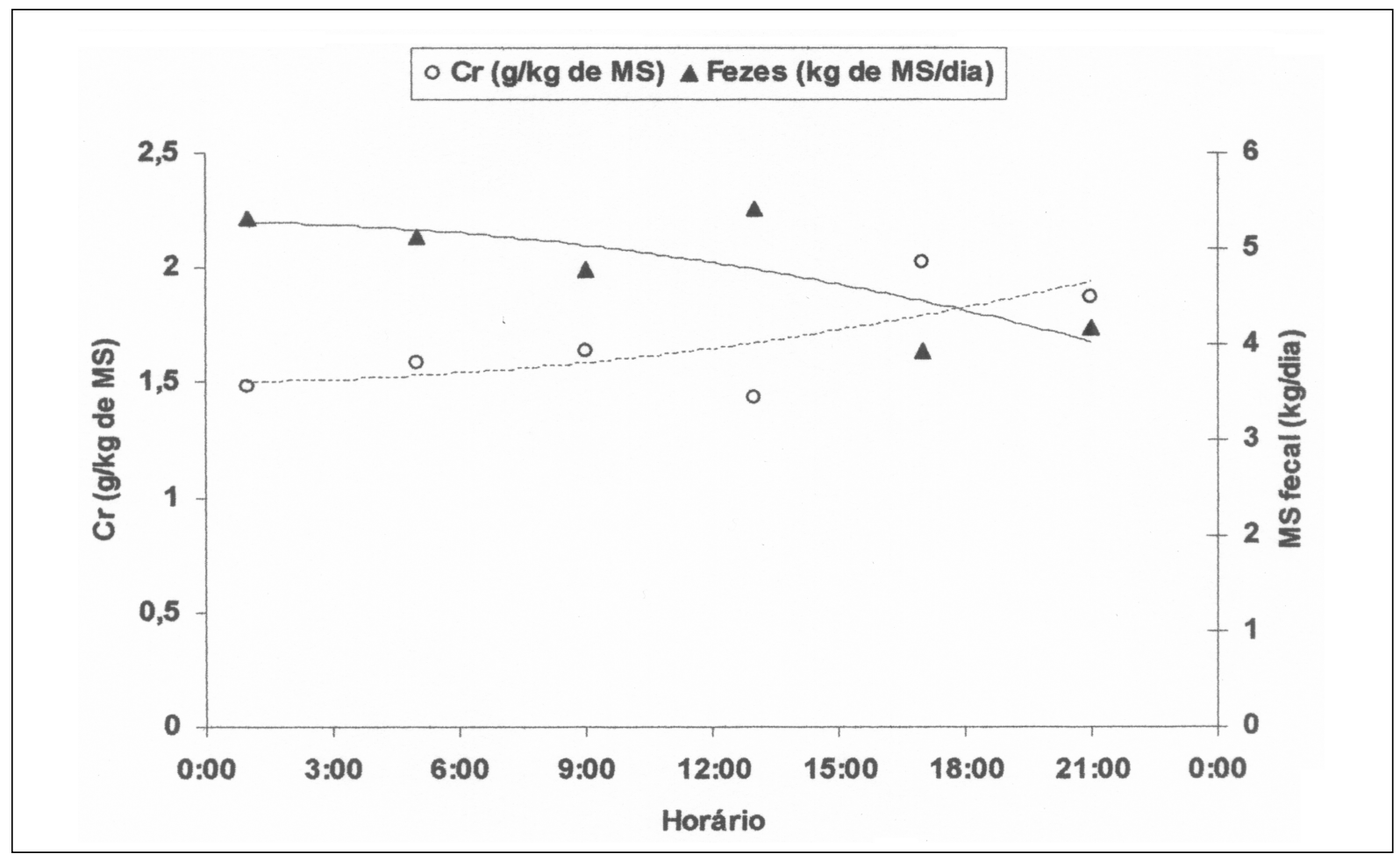

Figura 1 - Variação da concentração de cromo e da estimativa de produção fecal de vacas de leite em pastejo em função do horário de amostragem de fezes $\left(Y_{\text {cromo }}=1,50+0,01 X+0,55 X^{2}, r^{2}=0,53 ; Y_{\text {fezes }}=5,27-0,07 X-1,55 X^{2}, r^{2}=0,60\right)$

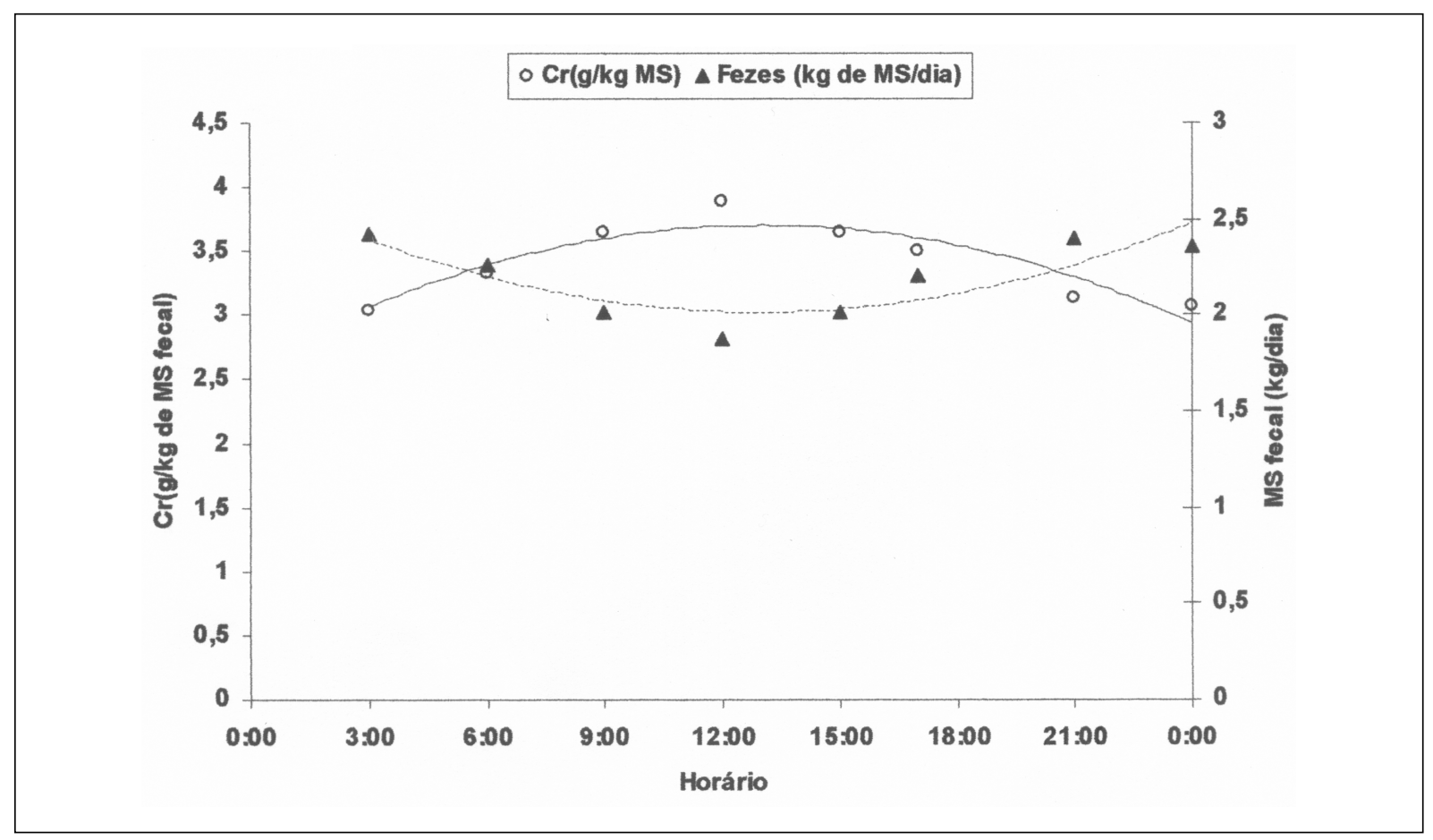

Figura 2 - Variação da concentração de cromo e da estimativa de produção fecal de novilhos de corte em pastejo em função do horário de amostragem de fezes $\left(\mathrm{Y}_{\text {cromo }}=2,62+3,99 \mathrm{X}-3,67 \mathrm{X}^{2}, \mathrm{r}^{2}=0,86 ; \mathrm{Y}_{\text {fezes }}=2,66-2,38 \mathrm{X}+2,20 \mathrm{X}^{2}, \mathrm{r}^{2}=0,73\right)$.

Ciência Rural, v.36, n.2, mar-abr, 2006. 
Tabela 1 - Concentração de cromo e estimativa da produção fecal de vacas de leite em pastejo com base em amostras fecais compostas de dois ou de seis horários de coleta ao longo de um período de 24 horas.

\begin{tabular}{lccccc}
\hline & Vacas & \multicolumn{4}{c}{ Protocolo de amostragem } \\
\hline & & 2 & $\mathrm{CV}^{2}$ & 6 & $\mathrm{CV}^{2}$ \\
Cr (g/kg de MS) & & $1,83^{\mathrm{a}}$ & 26,2 & $1,69^{\mathrm{a}}$ & 24,8 \\
$\begin{array}{l}\text { Produção fecal } \\
\text { (kg de MS/dia) }\end{array}$ & 24 & $4,36^{\mathrm{a}}$ & 26,3 & $4,75^{\mathrm{a}}$ & 23,6 \\
\hline
\end{tabular}

${ }^{1}$ Amostras compostas de dois (às 9:00 e às 17:00h) ou de seis horários (1:00, 5:00, 9:00, 13:00, 17:00 e 21:00h).

${ }^{2}$ Coeficiente de variação (\%) das médias, sendo que médias na mesma linha seguidas de mesma letra não diferem pelo teste $\mathrm{F}$ $(\mathrm{P}<0,05)$.

\section{AGRADECIMENTOS}

Os autores agradecem à Coordenação de Aperfeiçoamento de Pessoal de Nível Superior (CAPES) e ao Conselho Nacional de Desenvolvimento Científico e Tecnológico (CNPq) por uma bolsa do Programa de Absorção Temporária de Doutores (PRODOC/CAPES) e bolsas de pósgraduação.

\section{REFERÊNCIAS}

CZARNOCKI, J. et al. The determination of chromium oxide in samples of feed and excreta by acid digestion and
Tabela 2 - Concentração de cromo e estimativa da produção fecal de novilhos de corte em pastejo com base em amostras fecais compostas de dois ou de oito horários de coleta ao longo de um período de 24 horas.

\begin{tabular}{lccccc}
\hline & Novilhos & \multicolumn{4}{c}{ Protocolo de amostragem } \\
\hline & & 2 & $\mathrm{CV}^{2}$ & 8 & $\mathrm{CV}^{2}$ \\
Cr (g/kg de MS) & & $3,60^{\mathrm{a}}$ & 24,2 & $3,40^{\mathrm{a}}$ & 20,5 \\
$\begin{array}{l}\text { Produção fecal } \\
\text { (kg de MS/dia) }\end{array}$ & 36 & $2,10^{\mathrm{a}}$ & 30,9 & $2,20^{\mathrm{a}}$ & 18,2 \\
\hline
\end{tabular}

${ }^{1}$ Amostras compostas de dois (às 9:00 e 18:00h) ou de oito horários (3:00, 6:00, 9:00, 12:00, 15:00, 18:00, 21:00 e 24:00h). ${ }^{2}$ Coeficiente de variação (\%) das médias, sendo que médias na mesma linha seguidas de mesma letra não diferem pelo teste $\mathrm{F}$ $(\mathrm{P}<0,05)$.

spectrophotometry. Canadian Journal of Animal Science, v.4, p.167-179, 1961

DETMANN, E. et al. Cromo e indicadores internos na determinação do consumo de novilhos mestiços, suplementados, a pasto. Revista Brasileira de Zootecnia, v.30, p.16001609, 2001.

FAICHNEY, G.J. An assessment of chromic oxide as anindigestible marker for digestion studies in sheep. Journal of Agricultural Science, v.79, p.493-499, 1972.

SAS. Statistical Analysis System. Software, Version 8.02. Cary, 1999. CD ROM. 